OPEN ACCESS

Edited by:

Daniel Moore,

University of Toronto, Canada

Reviewed by:

Justin Roberts,

Anglia Ruskin University,

United Kingdom

Jess A. Gwin,

US Army Research Institute of Environmental Medicine (USARIEM),

United States

Tarja Nykänen,

Finnish Defence Forces, Finland

*Correspondence:

JoEllen M. Sefton

jms0018@auburn.edu

Specialty section:

This article was submitted to Sport and Exercise Nutrition,

a section of the journal

Frontiers in Nutrition

Received: 02 November 2021

Accepted: 25 January 2022

Published: 07 March 2022

Citation:

McAdam JS, Lyons KD, Beck DT, Haun CT, Romero MA, Mumford PW, Roberson PA, Young KC, Lohse KR,

Roberts MD and Sefton JM (2022)

Whey Protein Supplementation Effects on Body Composition, Performance, and Blood Biomarkers During Army Initial Entry Training

Front. Nutr. 9:807928.

doi: 10.3389/fnut.2022.807928

\section{Whey Protein Supplementation Effects on Body Composition, Performance, and Blood Biomarkers During Army Initial Entry Training}

\author{
Jeremy S. McAdam 1,2, Kaitlin D. Lyons ${ }^{1}$, Darren T. Beck ${ }^{3,4}$, Cody T. Haun ${ }^{3,5}$, \\ Matthew A. Romero ${ }^{3}$, Petey W. Mumford ${ }^{3}$, Paul A. Roberson ${ }^{3}$, Kaelin C. Young ${ }^{3,4}$, \\ Keith R. Lohse ${ }^{6}$, Michael D. Roberts ${ }^{3,4}$ and JoEllen M. Sefton ${ }^{1 *}$
}

\footnotetext{
${ }^{1}$ School of Kinesiology, Warrior Research Center, Auburn University, Auburn, AL, United States, ${ }^{2}$ Healthspan, Resilience, and Performance Research, Florida Institute for Human and Machine Cognition, Pensacola, FL, United States, ${ }^{3}$ Molecular and Applied Sciences Laboratory, School of Kinesiology, Auburn University, Auburn, AL, United States, ${ }^{4}$ Department of Cell Biology and Physiology, Edward Via College of Osteopathic Medicine (Auburn Campus), Auburn, AL, United States, ${ }^{5}$ Fitomics, LLC, Pelham, AL, United States, ${ }^{6}$ Neurorehabilitation Informatics Lab, Department of Health, Kinesiology, and Recreation, University of Utah, Salt Lake City, UT, United States
}

This study assesses if a lower dose of whey protein can provide similar benefits to those shown in previous work supplementing Army Initial Entry Training (IET) Soldiers with two servings of whey protein (WP) per day. Eighty-one soldiers consumed one WP or a calorie matched carbohydrate $(\mathrm{CHO})$ serving/day during IET (WP: $n=39$, height $=173 \pm 8 \mathrm{~cm}$, body mass $=76.8 \pm 12.8 \mathrm{~kg}$, age $=21 \pm 3$ years; $\mathrm{CHO}: n=42$, $175 \pm 8 \mathrm{~cm}, 77.8 \pm 15.3 \mathrm{~kg}, 23 \pm 4$ years). Physical performance (push-ups, sit-ups, and a two-mile run) was assessed during weeks two and eight. All other measures (dietary intake, body composition, blood biomarkers) at weeks one and nine. There was a significant group difference for fat mass $(p=0.044)$ as WP lost $2.1 \pm 2.9 \mathrm{~kg}$ and had a moderate effect size (Cohen's d: -0.24 ), whereas the $\mathrm{CHO}$ group lost $0.9 \pm 2.5 \mathrm{~kg}$ and had only a small effect size (d: -0.1$)$. There was no significant group-by-time interaction on fat-free mass ( $p=0.069)$. WP gained $1.2 \pm 2.4(\mathrm{~d}: 0.1)$ and $\mathrm{CHO}$ gained $0.1 \pm 3(\mathrm{~d}: 0)$ $\mathrm{kg}$ of FFM on average. There was a significant group by week 1 -fat free mass interaction $(p=0.003)$ indicating individuals with higher initial fat-free mass benefitted more from WP. There were no group differences for push-up $(p=0.514)$, sit-up $(p=0.429)$ or run $(p=0.313)$ performance. For all biomarkers there was a significant effect of time as testosterone $(p<0.01)$, testosterone to cortisol ratio $(p=0.39)$, and IGF-1 $(p<0.01)$ increased across training and cortisol $(p=0.04)$ and IL-6 $(p<0.01)$ decreased. There were no differences in groups across IET for any of the biomarkers. We conclude one WP serving is beneficial for FM and for FFM in soldiers with high baseline FFM but may not significantly alter biomarker response or physical performance of IET soldiers who have high relative dietary protein intakes.

Keywords: human performance, military, supplementation, fat free mass, fat mass 


\section{INTRODUCTION}

Improving physical fitness is key for the success of military personnel due to the strenuous nature of daily soldiering tasks $(1,2)$. Initial Entry Training (IET) is a physically and mentally rigorous training environment designed to prepare soldiers to perform their duties. Past research indicates that US Army IET soldiers participate in at least $6-7 \mathrm{~h}$ of daily physical activity, ranging from low to very vigorous intensity $(3,4)$. Recent research suggests Army IET soldiers may be inadequately fueled to respond optimally to large volumes of training (3). IET soldiers consume between 1,900-and 2,600 calories per day (3, $5)$. However, they are estimated to expend over 3,200 calories per day, resulting in a negative energy balance (3). This may have negative effects on performance and body composition (6). Research in US Army (5) and Marine (7) IET revealed that IET soldiers lost 1-3 kg of fat-free mass (FFM) on average across training, with only $36 \%$ of male Army IET soldiers gaining FFM during training (5). Losses in FFM may lead to decrements in physical performance for IET soldiers as has been found in non-IET in military training in the US and Australia $(8,9)$.

Serum biomarkers are one method of assessing responses to military training. Testosterone and Insulin-like Growth Factor 1 (IGF-1) are anabolic hormones that are positively related to body composition and performance due to their ability to stimulate anabolic mechanisms such as increased muscle protein synthesis $(10,11)$. While intense military training has been shown to reduce serum testosterone and IGF-1 (10), these reductions can be nutritionally modulated (12). Serum testosterone and IGF-1 are decreased during periods of negative energy balance across military training. These decreases can be restored to baseline levels when adequate nutritional provision is provided (12). Military training has also been shown to increase serum cortisol levels, a hormone that results in skeletal muscle catabolism (9, 12). The balance between anabolic and catabolic hormones is thought to be important for the promotion of muscle remodeling. Imbalances in the testosterone: cortisol (T:C) ratio, whether it is caused by decreases in testosterone or increases in cortisol, have been shown to be associated with reductions in performance (13). Studies in Army Rangers (12), Australian basic training (14), and United Kingdom section commanders' battle course (15) all report that military training results in elevated cortisol levels and a reduction in the $\mathrm{T}: \mathrm{C}$ ratio. Military training has also been reported to increase serum cytokine concentrations, such as interleukin-6 (IL-6), that stimulates the inflammatory response to muscle damage and pathogens (16-19). Studies in Norway and France show that military training can lead to increases in IL-6 acutely (four days) and chronically (four weeks) $(18,19)$. Chronically elevated levels of IL-6 have been related to overtraining and may represent inadequate recovery (20).

Nutritional supplementation may have an important influence on physical and hormonal responses to military training. One United Kingdom study (9) reported the addition of a proteinbased supplement negated the decrease in performance and FFM during 8 weeks of training. Our previous work in IET soldiers revealed supplementation with either a higher dose (two servings per day) of whey protein or a calorie-matched carbohydrate
$(\mathrm{CHO})$ resulted in a higher percentage of participants gaining FFM across IET in comparison to a previous investigation of non-supplemented IET soldiers $(5,21)$. Additionally, two servings per day of WP resulted in significantly higher pushup performance and potentiated reductions in fat mass (FM) in comparison to $\mathrm{CHO}$ (21). WP with small amounts of casein has been shown to increase IGF-1 and muscle mass in individuals involved in strength training (22). Another study (23) found that 6 months of protein supplementation resulted in increases in serum IGF-1 levels in individuals involved in concurrent strength and endurance training. The effects of protein supplementation on IGF-1 levels are thought to be mediated by an increased supply of amino acids that stimulate IGF-1 gene transcription in skeletal muscle (22). WP has also been reported to increase serum testosterone in comparison to soy, as well as to reduce serum cortisol levels in response to resistance training compared to soy and carbohydrate ( $\mathrm{CHO}$ ) supplementation (24). Collectively, these studies suggest that WP may be beneficial for improving the hormonal environment required to support advantageous physical performance and physiologic responses to IET.

The goal of the current study is to build upon our previous research examining the impact of WP supplementation on IET soldiers. Here we examined if one WP serving per day was more beneficial than $\mathrm{CHO}$ on performance, body composition, and serum-biomarker responses. If one WP serving per day provides similar benefits to those demonstrated with two WP servings per day, it would reduce preparation and distribution time, as well as supplementation costs for the military. Based on our prior data, we hypothesized WP would be beneficial for push-up performance and body composition. Additionally, we hypothesized that WP would be more beneficial than $\mathrm{CHO}$ for improvements in the T:C ratio and IGF-1 responses to training due to improvements in the anabolic status of the body as well as reductions in cortisol and IL-6 which may indicate improved recovery during IET.

\section{METHODS}

\section{Study Design and Population}

This was a double-blind, placebo-controlled, 2 × 2 (Group $\mathrm{x}$ Time) factorial-repeated measures design. The Auburn University Institutional Review Board, and the Director, Research, and Analysis Directorate Army Center approved the study procedures for Initial Military Training. Potential participants were given a description of the study. Those wishing to participate gave written consent and were enrolled in the study. Participants were cleared for military training and were apparently healthy 19-35-year-old men engaged in Army IET. All IET soldiers are required to live in barracks under the continual supervision of drill sergeants throughout the duration of IET. Daily schedules are highly regimented according to Army regulations from the time IET soldiers wake until time for bed. Daily physical fitness and occupational training events are performed in groups led by Army leadership. Daily activities consisted of morning group physical fitness (bodyweight resistance training, endurance training, general flexibility, and calisthenics) followed by soldier training tasks 
(ruck marching, obstacle course, land navigation, battle tactics training, field training exercises, etc.). All soldiers in the unit completed the same tasks for the same duration each week. All soldiers consumed food from the same menu, and meals were consumed from the dining facility or from pre-packaged meals ready to eat. Participants were free from musculoskeletal injury (MSI), allergies to milk or whey protein, and had not taken supplements within the past 3 months. In total 95 participants agreed to participate in the study, 81 participants completed the study (WP: $n=39$, height $=173 \pm 8 \mathrm{~cm}$, body mass $=76.8 \pm 12.8 \mathrm{~kg}$, age $=21 \pm 3$ years old; $\mathrm{CHO}$ : $n=42,175 \pm 8 \mathrm{~cm}, 77.8 \pm 15.3 \mathrm{~kg}, 23 \pm 4$ years old). A total of 14 participants were removed from the analysis due to prior supplementation (four participants), lack of adherence to supplementation (five participants), discontinued IET (four participants), and withdrawal of participation in the study (one participant).

Participants were supplemented with either one whey protein (Power Crunch ${ }^{\circledR}$ ProtoWhey ${ }^{\circledR}$ (BioNutritional Research Group; Irvine, CA, USA) as agglomerated, partially hydrolyzed $(12.5 \%$ degree of hydrolysis) $80 \%$ whey protein concentrate (Hilmar ${ }^{\circledR}$ 8360; Hilmar Ingredients, Hilmar, CA USA) or calorie-matched $\mathrm{CHO}$ supplement per day. Supplement manufacturing and formulation have been described previously (21). Briefly, all supplements were manufactured at JW Nutritional, LLC (Allen, TX, USA), a United States Food and Drug Administration cGMP-compliant facility independently audited and prequalified by Obvium*Q, LLC (Phoenix, AZ, USA), a GMP regulatory compliance firm. Personnel at JW Nutritional, LLC and C.M.L. (Lockwood, LLC; Draper, UT, USA) formulated supplements to match for taste. These entities also maintained blinding of groups, and each supplement was assigned a randomly generated item number. The research team and participants were blinded to the contents of the packets until data collection was completed. Manufacturing batch records for production of each of the supplements were reviewed by a trained, independent expert in dietary supplement quality control, taste, and assurance (C.M.L.) before approval for use within the present study. The nutritional profile and amino acid content of both supplements were third-party tested by Covance Laboratories, Inc. (Madison, WI, USA) to verify the identity, purity, potency, and composition of the packets. The nutritional profile is described below in Table 1. In order to minimize interference in the IET training schedule, each week, all supplement packs were provided to the drill sergeants for their respective platoon. The drill sergeants then provided the supplements to the IET soldiers who were instructed to consume the shakes before bedtime. To assess adherence, the research team checked the boxes that were delivered to ensure distribution and asked the IET soldiers to report the number of shakes missed during the study.

\section{Measures}

The independent variables were supplementation group (WP or $\mathrm{CHO}$ ) and time (week 1, week 9). Outcome variables were daily training volume, physical performance as measured by the Army Physical Fitness Test (APFT), body composition,
TABLE 1 | Supplement nutrition information.

\begin{tabular}{lcc}
\hline Macronutrient & WP Supplement & CHO Supplement \\
\hline Energy (kcal) & 293 & 291 \\
Protein (g) & 38.6 & 0.5 \\
Carbohydrate (g) & 19 & 63.4 \\
Fat (g) & 7.5 & 3.9 \\
Essential AA (g) & 20.1 & 0.1 \\
BCAA (g) & 9.5 & 0.0 \\
\hline
\end{tabular}

WP, Whey Protein supplement; $\mathrm{CHO}$, Carbohydrate supplement; Kcal, Kilocalories; g: grams; AA, Amino Acids; BCAA, Branched Chain Amino Acids.

dietary intake, serum biomarkers of anabolic status (testosterone, cortisol, IGF-1, T:C), and immune health/recovery (IL-6). Fasted blood and body composition were collected during weeks one and nine of training prior to breakfast and morning physical training. Urine-specific gravity (USG) testing was completed prior to all blood collections and body composition assessments to ensure hydration status. Participants with USG values above 1.03 were considered inadequately hydrated, given water to drink, and not allowed to proceed with testing until USG was below 1.03. Performance measures were performed during weeks two and eight of training. Figure 1 summarizes the timeline of measurements for each variable during this study.

\section{Physical Activity}

The methodology employed for the evaluation of physical activity levels has been previously reported in detail (3). Briefly, physical activity was estimated using Actigraph GTX monitors (Actigraph, Pensacola, FL, USA). Each week a different set of 20 participants (10 per supplement group) were asked to wear a monitor on their right hip (Actigraph protocol) for 1 week and not remove the monitor except to shower. Monitors were initialized prior to deployment and physical activity per day was estimated using Actilife software version 13.1.1 (Actigraph, Pensacola, FL, USA). Time spent in each category of physical activity was estimated using Sasaki vector magnitude 3 (VM3) (25). The following range of counts were used for each category of physical activity: Moderate = 2,690-6,166 counts/min (3-5.99 METs), Vigorous = 6,167-9,642 counts $/ \mathrm{min}$ (6-8.99 METs), and Very Vigorous $\geq 9,642$ counts/min ( $>9$ METs) (25). All VM3 counts below 200 counts/minute were classified as sedentary (26), and the difference between sedentary cut points and moderate cut points were classified as low intensity (201-2,689 counts/min). The sampling rate was $30 \mathrm{~Hz}$ (27) and for the physical activity data to be considered valid, wear time as estimated by Actilife software was a minimum of $600 \mathrm{~min}$ (26).

\section{Dietary Intake}

Diet logs were completed on three days during weeks one and nine of IET. A detailed description of this process has been previously reported (3). Briefly, members of the research team obtained the menu from the dining facility IET where soldiers were required to eat at and pre-filled the diet log with options available for that meal. Immediately after the meal the research 


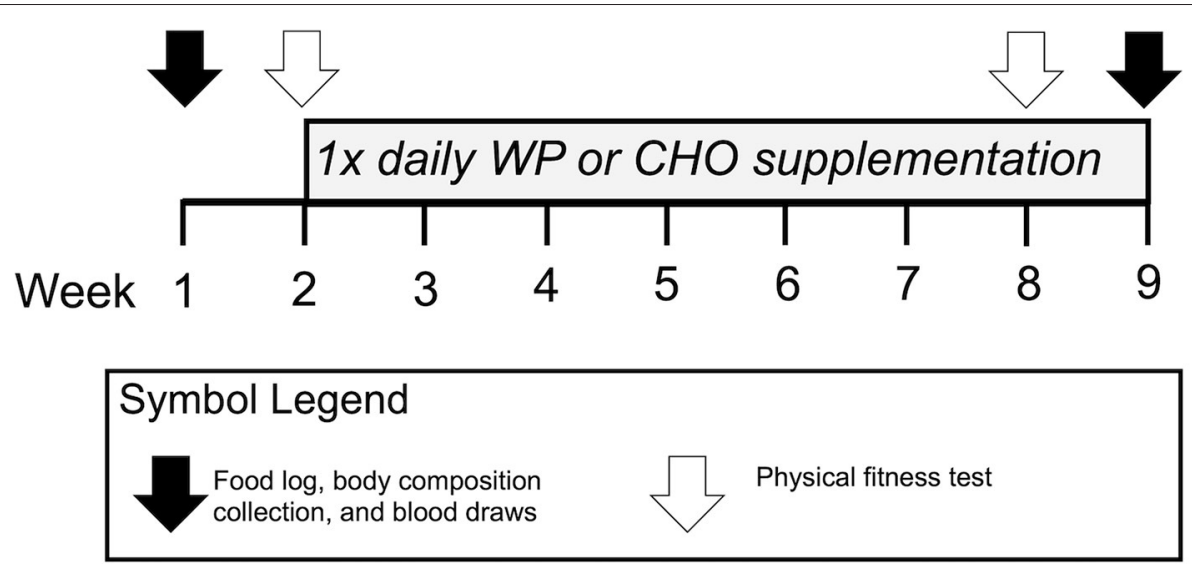

FIGURE 1 | Study timeline and measures. WP, Whey protein supplement group; CHO, Carbohydrate supplement group; 1x, Once daily.

team provided the diet logs to the participants to circle the items and amounts, they ate and were available to answer any questions. Diet log data was entered into excel spreadsheets and reviewed by two researchers for accuracy. The diet data were then imported into R statistical software (28) and dietary intake calculations were completed using R Studio (29) along with the $\mathrm{R}$ programming packages: dplyr (30), tidyr (31), reshape 2 (32), ez (33), car (34), vars (35), and ggplot2 (36). Total calorie, protein, carbohydrate, and fat intakes were calculated for each meal and day and then averaged for training weeks one and nine. Nutritional data for the dining facility foods were retrieved from the Army Joint Culinary Center of Excellence (JCOE) website and those not available on JCOE were retrieved from the US Department of Agriculture nutrition database (21). Diet logs for all three meals were required for the day to be considered valid for dietary analysis. Days in which a participant did not complete all three logs were removed from the analysis. Participants without at least two full days of diet logs each week were removed from the summary of diet logs. A total of 60 of the 81 participants who completed, had at least two full days of diet logs and were included in the dietary analysis. Diet logs during the first week were collected before the intervention period began in order to get a baseline characterization of dietary intake in the absence of supplementation (week 1-NS). We analyzed the dietary intake data in two ways: week 1-NS compared to week 9 dietary intake with supplement nutritional information included in the overall macronutrient count (week 9-SI) and excluding the macronutrient information from the overall macronutrient count (week 9-NS). Our aim was to see if there were significant changes in food that were consumed from the dining facility.

\section{Body Composition}

Height and body mass were assessed with participants wearing Army-issued physical training shorts, socks, and shirts using a Health-O-Meter professional scale (Model 500KL, Sunbeam products INC. Boca Raton, FL. USA) and reported in centimeters and kilograms. Body composition was assessed using an ImpediMed DF50 device (ImpediMed Ltd, Brisbane, Australia).
This measure is sensitive to hydration; therefore, hydration was assessed prior to measurement through urine-specific gravity (described above). Participants were asked to lay supine for $\sim 5$ min to allow for equilibration of body fluids across intracellular and extracellular compartments prior to assessment. Measurements were taken in the supine position. Electrode placement locations on the hand and ankle were determined as per the manufacturer's recommendations. An electrode was placed on the midline of the left arm proximal to the ulnar styloid process and a distal electrode was placed on the midline $5 \mathrm{~cm}$ apart. Electrodes were placed on the ankle on the midline between the medial and lateral malleolus and $5 \mathrm{~cm}$ distal to the malleolus on the midline. All application sites were shaved to ensure optimal electrode contact. All electrode placements were performed by the same member of the research team to minimize variability. Raw output was collected from the device, and fatfree 434 mass (FFM) and fat mass (FM) were calculated using the formulas below (37):

$$
\begin{aligned}
\mathbf{F F M}= & \frac{\text { Height }^{2}}{\text { Resistance }} * 0.734+B W * 0.116+\text { Reactance } \\
& * 0.096+1 * 0.878-4.03 \\
\mathbf{F M ~}= & \text { Body mass }- \text { Fat free mass }
\end{aligned}
$$

\section{Physical Performance}

The APFT was performed during weeks two and eight of the intervention. The APFT (fitness standard of record at the time of the study) consisted of a 2-min sit-up, 2-min pushup, and two-mile run. The APFT was administered by unit drill sergeants according to the standards of the US Army field manual for physical fitness training (1). Details describing APFT administration and criteria for Army standards for the proper performance of a push-up and sit-up and two-mile run have been described previously $(1,38)$.

\section{Serum Biomarkers}

Blood draws were taken from the antecubital vein via 21gauge, Safety-Lok needle kits (Benton, Dickinson, and Company, 
Franklin Lakes, NJ, USA). Blood was collected in $10 \mathrm{ml}$ serum separator vacutainer tubes (BD Vacutainer; Franklin Lakes NJ, USA) and placed on ice in a cooler (Yeti Coolers LLC, Austin TX, USA) until centrifugation the same morning of collection. Blood samples were centrifuged at 3,500 x $\mathrm{g}$ for $10 \mathrm{~min}$ at room temperature. Samples that were not fully separated were centrifuged again under the same conditions. Serum was extracted from separated blood and frozen at $-80^{\circ} \mathrm{C}$ until analysis. Testosterone (American Laboratory Products Company, Salem, NH, USA, sensitivity: $0.022 \mathrm{ng} / \mathrm{ml}, \mathrm{CV}: 2.9 \%$ ), cortisol (American Laboratory Products Company, Salem, NH, USA, sensitivity: $0.4 \mu \mathrm{g} / \mathrm{dL}, \mathrm{CV}: 4.8 \%$ ), IGF-1 (American Laboratory Products Company, Salem, NH, USA, sensitivity: $0.091 \mathrm{ng} / \mathrm{ml}, \mathrm{CV}:$ 10.5\%), and IL-6 (Invitrogen, Carlsbad, CA, USA, sensitivity: $0.3 \mathrm{pg} / \mathrm{ml}, \mathrm{CV}$ : $7.1 \%$ ) were measured using ELISAs according to manufacturers' instructions. Plates were analyzed at respective wavelengths using a multispectral spectrophotometer (BioTek Eon, Winooski, VT, USA). All samples were analyzed in duplicate, and each participant's weeks 1 and 9 samples were analyzed on the same plate. All-optical densities were within the detectable range of the assays. IL-6 had four individuals whose concentrations could not be used due to being outside the normal physiologic range for the four-compartment logistic regression models and were removed from the analysis. Serum concentrations of each optical density were calculated as per manufacturer instructions using either regression or a four-parameter logistic regression.

\section{Statistical Analysis}

For statistical analysis, ANOVA was used to compare diet and serum markers between groups and across the time of the intervention. The assumption of normality of residuals testing was completed for all variables using Shapiro-Wilks (W: Wilk's Statistic), Kolmogorov Smirnov tests, and residual QQ plots were used to visually inspect the data. Data were square-root transformed and normality was recalculated for any variable for which more than $75 \%$ of the levels were non-normally distributed. An a priori alpha level of 0.05 was set for the determination of significant effects. Maulchy's test of sphericity was used to evaluate equality of variance and Levene's test was used to evaluate the homogeneity of variance. If sphericity was violated a Greenhouse-Geisser correction was used. Group-bytime interactions were further evaluated using paired samples $t$-test to evaluate simple main effects of time and independent samples $t$-tests were used to evaluate the simple main effect of the group.

ANCOVA was used to evaluate performance and body composition. ANCOVA has been reported to increase sensitivity to factors specified by the study design (39). Mean centered initial values for each variable were used as the covariate in the ANCOVA model.

A mixed-design ANOVA was used to detect differences in average time spent per week training across our independent variables of the training week and supplement group. Our aim with this analysis was to determine if training volume across each intensity (low, moderate, vigorous, or very vigorous) was significantly different between supplement groups and/or across each week of IET. We employed a Tukey HSD post-hoc test for pairwise comparisons.

Cohen's $d$ effect sizes were calculated within groups across training, as well as between groups at week 9. Effect sizes are reported as effect sizes with the associated upper and lower limits of the $95 \%$ CI. Calculations are provided below:

$$
\begin{aligned}
\text { Effect Size } & =\text { mean }(\text { week } 9) \\
& - \text { mean }(\text { week } 1) / \text { pooled standard deviation }
\end{aligned}
$$

$$
\begin{aligned}
\text { Pooled standard deviation } & =\text { Square root }\left(\left(S D(\text { week } 1)^{2}\right.\right. \\
& \left.\left.+S D(\text { week } 9)^{2}\right) / 2\right)
\end{aligned}
$$

Testosterone violated assumption of normality at all levels (WP $=$ $\mathrm{W}: 0.78, p<0.01$ week 1 ; W: 0.7, $p<0.01$ week 9; $\mathrm{CHO}=\mathrm{W}: 0.8$, $p<0.01$ week 1 ; W: $0.7, p<0.01$ week 9). Testosterone was logtransformed and re-tested for normality. Only the week 9 data were non-normally distributed, but ANOVA is robust to partial violations of normality, so we chose to proceed with the analysis. IL-6 concentrations were log transformed and normality was retested. Following log transformation all levels of the variable were normally distributed.

\section{RESULTS}

\section{Physical Activity}

There was no statistical difference between groups for volume of training. This is indicated by a lack of significant difference between groups for light $(\mathrm{F}[1]=0.18, p=0.67)$, moderate $(\mathrm{F}[1]$ $<0.01, p=0.97)$, vigorous $(\mathrm{F}[1]=0.03, p=0.86)$ or very vigorous $(\mathrm{F}[1]=0.9, p=0.35)$ activity. There was a significant difference in light $(\mathrm{F}[2,100]=5.12, p<0.01)$ and moderate $(\mathrm{F}[2$, $100]=7.02, p<0.01)$, but not vigorous $(\mathrm{F}[2,100]=1.41, p=$ $0.25)$ or very vigorous $(\mathrm{F}[2,100]=2.42, p=0.09)$ activity levels across phase of IET. For light intensity, post-hoc testing revealed red phase was significantly higher than blue (adj. $p=0.05$ ) and white (adj. $p=0.01$ ) phases. For Moderate intensity white phase was lower than red (adj. $\mathrm{p}=0.02$ ) and blue (adj. $p<0.01$ ) phases. Total training time was only found to be significantly different between white and red phase as red phase was on average $50 \mathrm{~min}$ higher than white (adj. $p=0.01$ ). Table 2 below summarizes the training volume during each phase.

\section{Dietary Intake}

Baseline diet was collected prior to integration of supplementation. Differences in dietary intake from the dining facility alone, between groups across IET without supplement nutritional information, and comparisons on both absolute and relative dietary intake (normalized to body weight in $\mathrm{kg}$ ) were generated. Statistical results are listed below, and descriptive results are shown in Table 3.

\section{Dietary Intake From Meals Only}

Nutritional intake with no supplementation is presented in Table 3. There were no statistical differences between groups, 
TABLE 2 | Summary of training volume per phase IET.

\begin{tabular}{llccccc}
\hline Phase & Group & Light & Moderate & Vigorous & Very Vig. & Total \\
\hline Red & CHO & $303(37)$ & $110(23)^{\star}$ & $23(13)$ & $5(2)$ & $441(57)^{\star}$ \\
& WP & $300(41)$ & $105(23)^{\star}$ & $26(18)$ & $6(3)$ & $437(66)^{\star}$ \\
\multirow{4}{*}{ White } & CHO & $274(36)^{+}$ & $92(21)$ & $19(16)$ & $5(4)$ & $391(61)$ \\
& WP & $272(48)^{+}$ & $91(28)$ & $18(11)$ & $6(5)$ & $388(78)$ \\
Blue & CHO & $278(49)^{+}$ & $110(31)^{\star}$ & $28(40)$ & $3(3)$ & $419(93)$ \\
& WP & $271(54)^{+}$ & $122(41)^{\star}$ & $27(33)$ & $4(4)$ & $424(106)$ \\
\hline
\end{tabular}

Phase, Red (weeks 1-3), White (weeks 4-6), Blue (weeks 7-9); WP, Whey protein supplement group; $\mathrm{CHO}$, Carbohydrate supplement group; All values are in min/day \pm $S D$ values parenthesized. Very Vig.: very vigorous.

+ Indicates significantly different from Red Phase.

"Indicates significantly different from White Phase.

TABLE 3 | Summary of dietary intake across IET.

\begin{tabular}{|c|c|c|c|c|c|}
\hline Nutrient & Group & Units & Week 1-NS & Week 9-NS & Week 9-SI \\
\hline \multirow[t]{4}{*}{ Energy } & $\mathrm{CHO}$ & kcal/day & $2,759(585)$ & $3,472(697)^{+}$ & $3,763(697)$ \\
\hline & $\mathrm{CHO}$ & $\mathrm{kcal} / \mathrm{kg} /$ day & $37.4(11.4)$ & $46.7(12.2)^{+}$ & $50.6(12.7)$ \\
\hline & WP & $\mathrm{kcal} /$ day & $2,620(626)$ & $3,163(765)^{+}$ & $3,456(765)$ \\
\hline & WP & $\mathrm{kcal} / \mathrm{kg} /$ day & $34.7(10.8)$ & $42.1(11.9)^{+}$ & 46 (12.2) \\
\hline \multirow[t]{4}{*}{ Protein } & $\mathrm{CHO}$ & g/day & $122(26)$ & $163(29)^{+}$ & $163(29)^{+^{*}}$ \\
\hline & $\mathrm{CHO}$ & $\mathrm{g} / \mathrm{kg} /$ day & $1.7(0.5)$ & $2.2(0.5)^{+}$ & $2.2(0.5)^{+^{*}}$ \\
\hline & WP & g/day & $118(26)$ & $148(30)^{+}$ & $186(30)^{+^{*}}$ \\
\hline & WP & $\mathrm{g} / \mathrm{kg} /$ day & $1.6(0.4)$ & $2(0.5)^{+}$ & $2.5(0.5)^{+^{*}}$ \\
\hline \multirow[t]{4}{*}{ CARB } & $\mathrm{CHO}$ & g/day & $359(90)$ & $456(105)^{+}$ & $519(105)^{+*}$ \\
\hline & $\mathrm{CHO}$ & $\mathrm{g} / \mathrm{kg} /$ day & $4.9(1.6)$ & $6.1(1.8)^{+}$ & $7(1.9)^{+^{\star}}$ \\
\hline & WP & g/day & 342 (92) & $423(114)^{+}$ & $442(114)^{+*}$ \\
\hline & WP & $\mathrm{g} / \mathrm{kg} /$ day & $4.5(1.5)$ & $5.6(1.7)^{+}$ & $5.9(1.7)^{+^{*}}$ \\
\hline \multirow[t]{4}{*}{ Fat } & $\mathrm{CHO}$ & g/day & 95 (19) & $112(27)^{+}$ & $116(27)$ \\
\hline & $\mathrm{CHO}$ & $\mathrm{g} / \mathrm{kg} /$ day & $1.3(0.4)$ & $1.5(0.4)^{+}$ & $1.6(0.4)$ \\
\hline & WP & g/day & $90(23)$ & $99(27)^{+}$ & $107(27)$ \\
\hline & WP & $\mathrm{g} / \mathrm{kg} /$ day & $1.2(0.4)$ & $1.3(0.4)^{+}$ & $1.4(0.4)$ \\
\hline
\end{tabular}

Values are represented as mean ( $\pm S D$ ). Week 1 of IET; Week nine of IET; Week 1 NS: Week 1-training, no supplement nutrition included in total; Week 9-NS: Week 9, no supplement nutrition information included; Week 9-SI: Week 9 with supplement nutrition information added to the total. WP, Whey protein supplement group; $\mathrm{CHO}$, Carbohydrate supplement group.

*Indicates significant group difference at the respective time point.

+ Indicates a significant effect of time (Week 1 vs. Week 9).

A priori set at $p<0.05$.

calories, or macronutrients consumed from the dining facility across IET. This is indicated by a lack of significant group by time interactions for absolute calorie $(\mathrm{F}[1,60]=1.1, p=0.3)$, protein $(\mathrm{F}[1,60]=2.03, p=0.16)$, fat $(\mathrm{F}[1,60]=1.44, p=0.24)$, carbohydrate $(\mathrm{F}[1,60]=0.43, p=0.51)$, cholesterol $(\mathrm{F}[1,60]=$ $0.54, p=0.47)$, and sodium $(\mathrm{F}[1,60]=0.58, p=0.45)$ intake. This was also true when intakes were normalized to body weight. There were no significant group by time interactions for calorie $(\mathrm{kcal} / \mathrm{kg} ; \mathrm{F}[1,60]=0.65, p=0.42)$, protein $(\mathrm{g} / \mathrm{kg} ; \mathrm{F}[1,60]=1.31$, $p=0.26)$, fat $(\mathrm{g} / \mathrm{kg} ; \mathrm{F}[1,60]=0.89, p=0.35)$, carbohydrate $(\mathrm{g} / \mathrm{kg}$; $\mathrm{F}[1,60]=0.25, p=0.62)$, cholesterol $(\mathrm{mg} / \mathrm{kg} ; \mathrm{F}[1,60]=0.36, p=$ $0.55)$, and sodium $(\mathrm{mg} / \mathrm{kg} ; \mathrm{F}[1,60]=0.15, p=0.7)$.
Both groups significantly increased consumption of absolute energy $(\mathrm{F}[1,60]=50.27, p<0.01)$, protein $(\mathrm{F}[1,60]=66.01$, $p<0.01)$, fat $(\mathrm{F}[1,60]=15.14, p<0.01)$ and carbohydrate $(\mathrm{F}[1,60]=44.39, p<0.01)$ from week 1 to week 9. This finding remained significant when these macronutrients were normalized to body weight, as there were also main effects of time for calorie $(\mathrm{F}[1,60]=59.58, p<0.01)$, protein $(\mathrm{F}[1,60]=$ $78.06, p<0.01)$, fat $(\mathrm{F}[1,60]=17.29, p<0.01)$, and carbohydrate $(\mathrm{F}[1,60]=52.9, p<0.01)$.

\section{Dietary Intake With Supplements Included}

Nutritional information with supplementation values added to the week 9 dietary intake after week one are presented in Table 3. There was a significant group by time interaction for protein, absolute $(\mathrm{F}[1,60]=11.86, p<0.01)$, relative $(\mathrm{g} / \mathrm{kg} ; \mathrm{F}[1,60]=$ 10.89, $p<0.01)$, and carbohydrate, absolute $(\mathrm{F}[1,60]=6.15$, $p=0.02)$ and relative $(\mathrm{g} / \mathrm{kg} ; \mathrm{F}[1,60]=4.73, p=0.03)$. Posthoc $t$-tests to assess differences indicated both WP and $\mathrm{CHO}$ groups increased absolute protein intake across IET. The WP group increased protein intake on average 68 grams $(t=15.62$, $p<0.001)$ and CHO increased on average 41 grams $(t=5.24$, $p<0.001)$. There was no statistical difference between protein intake at baseline between groups $(t=0.6, p=0.552)$, however there was a significant difference at week $9(-3.04, p=0.004)$. There was a significant increase in absolute carbohydrate intake across IET in both the WP $(t=6.2, p<0.001)$ and $\mathrm{CHO}(t$ $=5.84, p<0.001)$ groups. There was no significant difference in carbohydrate intake at baseline $(t=0.73, p=0.469)$, but there were significant differences at week $9(t=2.77, p=0.007)$. Similar findings existed when protein and carbohydrate were normalized to body weight. There were significant increases in relative protein (WP: $t=14.87, p<0.01$; CHO: $t=4.02, p$ $<0.01)$ and carbohydrate $(t=5.82, p<0.01, t=4.57, p<$ 0.01 ) intakes across IET in both the WP and $\mathrm{CHO}$ groups. For relative protein and carbohydrate intake there were no significant differences in intakes at baseline (protein-baseline: $t=0.82, p$ $=0.42$, carbohydrate baseline: $t=0.86, p=0.39$ ), but there were differences at week 9 (protein-week 9: $t=-2.06, p=0.04$, carbohydrate-week 9: $t=2.44, p=0.02$ ).

\section{Body Composition}

A total of 81 participants were included in the analysis of body composition (BM, FM, FFM). Descriptive statistics and effect sizes are reported in Table 4. For BM, mean-centered week 1-BM was a significant predictor of week $9 \mathrm{BM}(\mathrm{F}=1,420.3, p<0.001)$. However, there were no group $(\mathrm{F}=0.13, p=0.722)$ or group by week 1-BM interactions $(\mathrm{F}=0.74, p=0.393)$.

There was a significant group by week 1-FFM interaction (F $=9.46, p=0.003$ ) on week 9 FFM and a significant interaction for week 1-FFM and group, thus the main effects could not be interpreted. Therefore, we conducted two follow-up analyses. First, linear models were fitted to the WP and CHO groups separately to investigate the influence of baseline FFM on the response to the treatment. Next, we conducted a standard groupby-time ANOVA to gain insight into the change across time in FFM between the groups. The interaction plot (Figure 2) below shows a trend in the relationship between baseline FFM and 
TABLE 4 | Summary of body composition and performance.

\begin{tabular}{llcccc}
\hline Variable & Group & Week 1 & Week 9 & Mean Difference [Cl] & Effect Size \\
\hline BM (kg) & CHO & $77.8(15.3)$ & $76.9(13.1)$ & $-0.8[-8,6.3]$ & -0.04 \\
& WP & $76.8(12.8)$ & $75.8(11.6)$ & $-0.9[-7.5,5.7]$ & -0.05 \\
FFM (kg) & CHO & $61.4(10.5)$ & $61.5(8.7)$ & $0.1[-5.8,5.9]$ & 0 \\
& WP & $59.5(8.4)$ & $60.7(8.5)$ & $1.2[-3.5,5.8]$ & 0.1 \\
FM (kg) & CHO & $16.3(6.6)$ & $15.4(5.7)$ & $-0.9[-5.9,4.1]$ & -0.1 \\
& WP & $17.2(7)$ & $15.1(5.2)$ & $-2.1[-7.8,3.6]$ & -0.24 \\
& & Week 2 & Week 8 & & \\
Run (sec) & CHO & $965(146)$ & $849(77)$ & $-116[-280,47]$ & -0.7 \\
& WP & $981(144)$ & $870(85)$ & $-112[-284,60]$ & -0.67 \\
PU (reps) & CHO & $44(17)$ & $51(14)$ & $8[-17,33]$ & 0.35 \\
& WP & $36(18)$ & $48(15)$ & $12[-6,30]$ & 0.52 \\
SU (reps) & CHO & $51(14)$ & $66(11)$ & $15[-0.3,31]$ & 0.86 \\
& WP & $44(15)$ & $60(13)$ & $16[-9,40]$ & 0.8 \\
\hline
\end{tabular}

Raw values are represented as mean $( \pm S D)$. Mean difference: the average difference across IET with 95\% Cls at weeks 1 and 9 for BM, FFM, and FM and weeks 2 and 8 for Run, PU, and SU. Effect size, Cohen's D; BM, Body Mass; FFM, Fat-Free Mass in kg; FM, Fat Mass in kg; Run: two-mile run time in seconds; PU, Push-ups completed in 1 min; SU, Sit-ups completed in $1 \mathrm{~min}$; $\mathrm{kg}$, kilogram; sec, seconds; reps, number of repetitions completed; WP, Whey protein supplement group; CHO, Carbohydrate supplement group.

week 9 FFM depending on the group. For every $1 \mathrm{~kg}$ increase in baseline FFM, there was a related $0.97 \mathrm{~kg}$ increase in FFM at week 9 in the WP group compared to a $0.8 \mathrm{~kg}$ increase in FFM at week 9 in the $\mathrm{CHO}$ group. The coefficients from the multiple regression model (ANCOVA with the significant group by week 1-FFM interaction) were used to predict week 9-FFM as an illustration of the interaction of week 1-FFM and supplement group. If a soldier began IET at $5 \mathrm{~kg}$ above average in FFM the predicted week 9-FFM would be $1.76 \mathrm{~kg}$ higher if the soldier were in the WP group than if the soldier were in the $\mathrm{CHO}$ group. However, if the soldier were $5 \mathrm{~kg}$ below average, week $9 \mathrm{FFM}$ is predicted to be only $0.04 \mathrm{~kg}$ higher if the IET soldier were in the WP vs. the $\mathrm{CHO}$ group. If these are extended to being $10 \mathrm{~kg}$ above or below average FFM beginning IET, the soldier who is $10 \mathrm{~kg}$ above average would be expected to have a week 9 FFM $2.62 \mathrm{~kg}$ higher if given WP vs. $\mathrm{CHO}$, whereas if the soldier were $10 \mathrm{~kg}$ below average, the expected FFM at week 9 would be 0.81 lower if the soldier were in the WP vs. the CHO group. The group by time ANOVA trended toward significance $(\mathrm{F}=3.38, p=0.07)$. The WP group increased FFM $1.2 \mathrm{~kg}$ on average and the $\mathrm{CHO}$ group increased by $0.1 \mathrm{~kg}$ on average, suggesting that WP may be beneficial for FFM response to IET. Both groups increased FFM across IET as there was a significant effect of time $(\mathrm{F}=4, p=0.05)$.

For FM, there was no group by week 1-FM interactions $(\mathrm{F}=$ $2.26, p=0.137)$. Mean centered week 1-FM $(\mathrm{F}=456, p<0.001)$ and group $(\mathrm{F}=4.18, p=0.044)$ were significant factors for week 9 FM. WP lost $2.1 \mathrm{~kg}$ on average of FM across IET whereas the $\mathrm{CHO}$ group lost $0.9 \mathrm{~kg}$.

\section{Physical Performance}

We were only able to obtain performance data from three out of the four platoons, creating an imbalance in sample size between groups for performance metrics. In total, there were

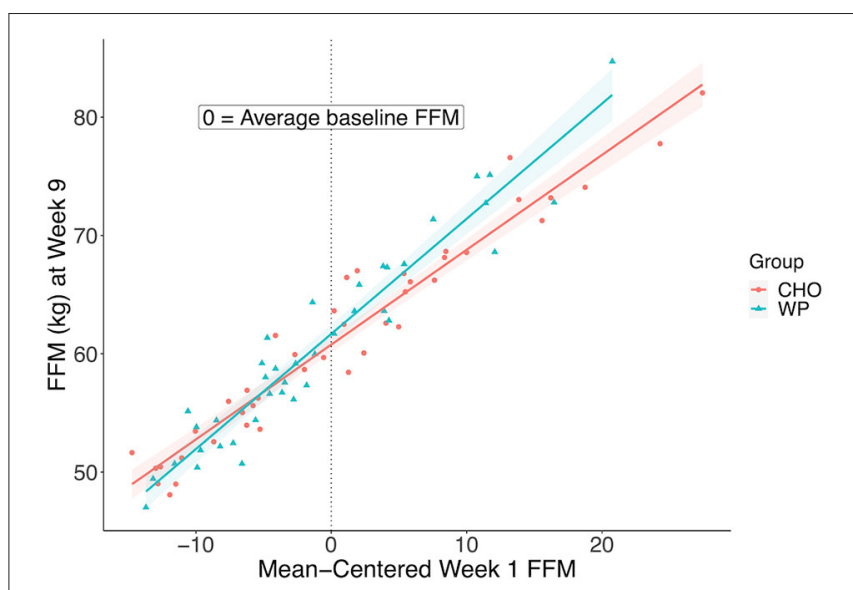

FIGURE 2 | Interaction between baseline and Week 9 FFM between groups. Plot of Week 9 FFM in kilograms and mean-centered Week 1 FFM to display the relationship between groups. FFM, Fat-Free Mass; $\mathrm{CHO}$, carbohydrate supplement group; WP, Whey protein supplement group.

57 participants $(\mathrm{WP}=37, \mathrm{CHO}=18)$ data included in the analysis for push-ups and sit-ups, and 56 participants (WP $=$ 36 , $\mathrm{CHO}=18$ ) for run. For sit-ups, mean centered week 1sit-up performance was a significant predictor of week 9-situp performance $(\mathrm{F}=43.85, p<0.001)$. However, there were no group $(\mathrm{F}=0.64, p=0.429)$ or group by week 1 -sit-up interactions $(\mathrm{F}=0.16, p=0.694)$. For push-ups, mean centered week 1-push-up performance was a significant predictor of week 9 push-up performance $(\mathrm{F}=96.94, p<0.001)$. However, there were no group $(\mathrm{F}=0.43, p=0.514)$ or group by week 1-pushup interactions $(\mathrm{F}=0.97, p=0.33)$. For run performance, mean centered week 1-run performance was a significant predictor of week 9-run performance $(\mathrm{F}=133.52, p<0.001)$. However, there were no group $(\mathrm{F}=1.04, p=0.313)$ or group by week 1 -run interactions $(\mathrm{F}=0.02, p=0.899)$.

\section{Serum Biomarkers}

A total of 48 participants ( $\mathrm{WP}=23, \mathrm{CHO}=25$ ) were included in the analysis of serum testosterone. The ANOVA was conducted on the log transformed testosterone data due to violation of the assumption of normality of residuals. There was a significant main effect of time $(\mathrm{F}=13.74, p<0.01)$, however, there was no main effect of group $(\mathrm{F}=0.89, p=0.35)$ or group by time interactions $(\mathrm{F}=0, p=0.95)$. A total of 47 participants $(\mathrm{WP}=$ $23, \mathrm{CHO}=25$ ) were included in the analysis of serum cortisol. There was a significant main effect of time $(\mathrm{F}=4.38, \mathrm{p}=0.04)$, however, there was no main effect of group $(\mathrm{F}=0.34, p=0.56)$ or group by time interactions $(\mathrm{F}=1.88, p=0.18)$. A total of 48 participants $(\mathrm{WP}=23, \mathrm{CHO}=25)$ were included in the analysis of serum T:C. There was a significant main effect of time $(\mathrm{F}=$ $20.15, p<0.01)$, however, there was no main effect of group $(\mathrm{F}=$ $0.75, p=0.39)$ or group by time interactions $(\mathrm{F}=0.8, p=0.38)$.

A total of 48 participants $(\mathrm{WP}=23, \mathrm{CHO}=25)$ were included in the analysis of serum IGF-1. There was a significant main effect of time $(\mathrm{F}=8.07, p<0.01)$, however, there was no main effect of 
group $(\mathrm{F}=2.81, p=0.1)$ or group by time interactions $(\mathrm{F}=1.30$, $p=0.26)$. Lastly, we investigated the effects of supplementation on IL-6, a marker of inflammation. A total of 36 participants (WP $=17, \mathrm{CHO}=19$ ) were included in the analysis of serum IL6. Due to violation of the assumption of normality of residuals, the ANOVA was conducted on the log transformed IL- 6 data. There was a significant main effect of time $(\mathrm{F}=17.92, p<0.01)$, however, there was no main effect of group $(\mathrm{F}=0.02, p=0.9)$ or group by time interactions $(\mathrm{F}=0.15, p=0.71)$. The biomarker responses are summarized in Figure 3.

\section{DISCUSSION}

This project examined if 8 weeks of a single daily serving of WP compared to $\mathrm{CHO}$ supplementation influenced physical performance, blood biomarkers, and body composition across IET. Our primary findings were: (1) WP was related to a significant reduction in FM during IET; (2) WP had differential effects on FFM depending on the soldiers' FFM upon entry into IET; (3) there was no statistically significant benefit between supplements for physical performance or the anabolic or inflammatory biomarker response to IET. Two important secondary findings were that soldiers increased dietary intake from meals across IET and that training volume was higher in the initial phases of IET in comparison to the later phases. Below we discuss these findings and how these findings (with once-daily WP supplementation) relate to our findings using twice daily supplementation with WP daily in the same population.

Soldiers consuming WP daily had a significant reduction in FM during IET. The WP group lost an additional $1.2 \mathrm{~kg}$ of $\mathrm{FM}$ with a larger effect size than $\mathrm{CHO}(\mathrm{WP}=-0.24, \mathrm{CHO}=$ -0.1 ). There were no significant differences in overall caloric intake or training volume completed between groups. Thus, the losses in FM seen here were likely not influenced by those variables. This is similar to our previous work in IET soldiers that found a significant reduction in FM in the WP group that consumed 2 servings ( $80 \mathrm{~g}$ total) of WP daily. IET soldiers consuming 2 servings per day lost an additional $1.8 \mathrm{~kg}$ of FM in comparison to the group consuming two $\mathrm{CHO}$ servings per day. The potential impact of WP on FM agrees with studies in non-military populations as well $(40,41)$. WP has been shown to promote FM loss in conjunction with exercise in healthy $(41,42)$

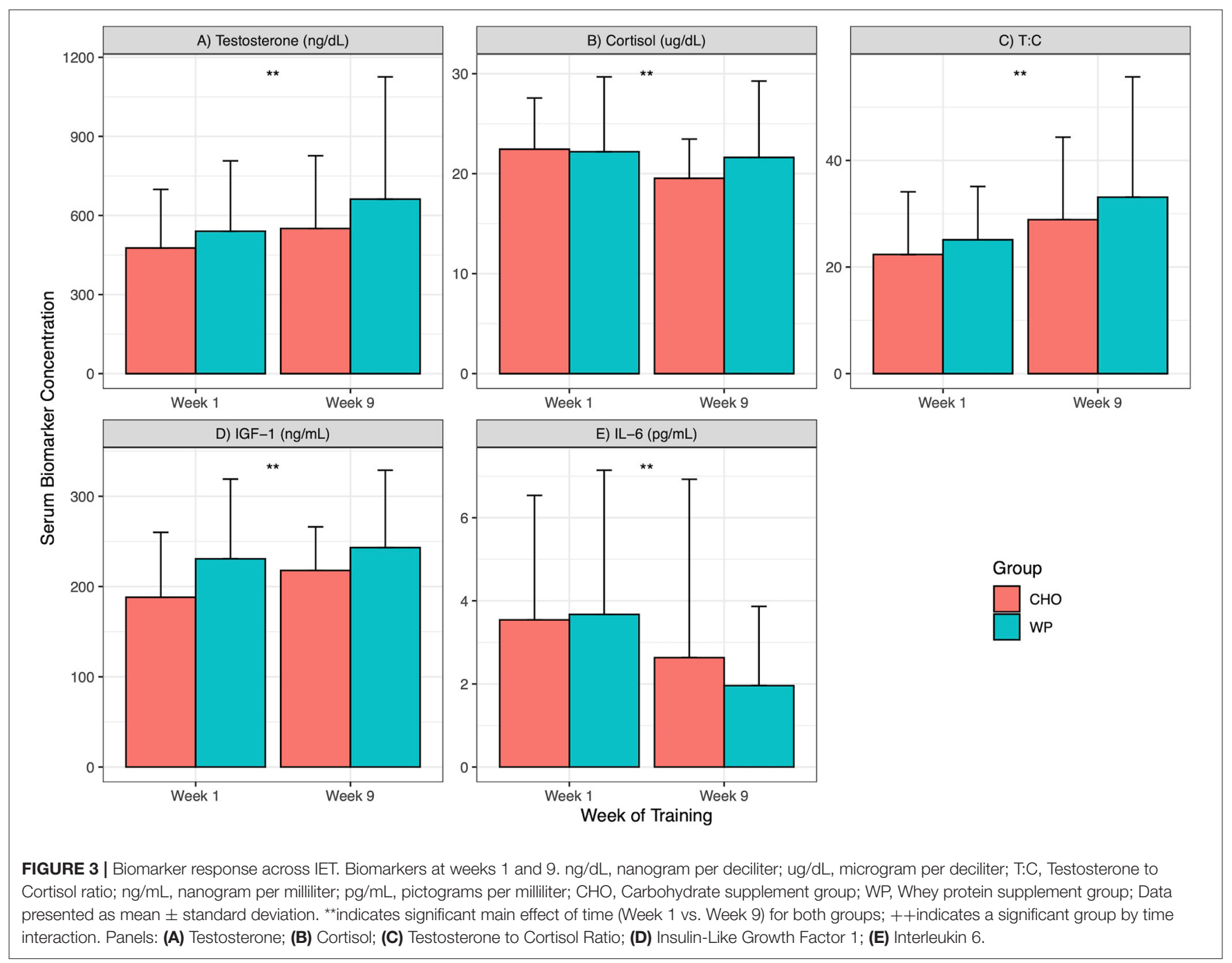


and obese individuals $(40,41)$. Animal and cell culture models suggest WP may promote fat metabolism by influencing both adipose and muscle $(43,44)$. WP has been shown to impact adipose tissue by upregulating signaling pathways associated with the breakdown of triglycerides into FFA $(43,44)$, fat oxidation (45), thermogenesis (43), and antagonists to fatty acid synthesis (44). Conversely, in myotubes, WP has been shown to upregulate signaling pathways related to free fatty acid transport to mitochondria (43) and mitochondrial ability to oxidize free fatty acids (44). Additionally, myotubes cultured in serum from humans who consumed WP in the fasted state had improved GLUT4 translocation which would promote uptake of glucose to the muscle (46). Thus, WP may contribute to FM reductions by promoting the breakdown of adipose, suppressing the synthesis of FFA, and improving transport and oxidation of free fatty acids in both adipose and muscle tissue. Another potential way WP can impact FM is the thermic effect of food. Previous work has shown that protein has a higher thermic effect than both carbohydrate and fat intake (47). WP has been shown to increase the thermic effect of food (48) and to a greater extent than other protein sources such as soy and casein (49). Therefore, WP supplementation may be a viable option for IET soldiers and individuals who are engaging in exercise training while trying to reduce FM.

WP was also found to be more beneficial for FFM in individuals who had higher FFM at week 1 relative to soldiers with lower FFM and those in the $\mathrm{CHO}$ group. This is evidenced by the significant group by baseline FFM interaction. We then used the multivariate model to predict what a soldier's week 9 FFM would be if the individual were in the WP vs. the $\mathrm{CHO}$ group at different baseline FFM $(5,10 \mathrm{~kg}$ above or below average). In summary, an individual who has higher FFM at week 1 would have a higher predicted week 9 FFM if he were in the WP vs. the $\mathrm{CHO}$ group. Interestingly, we followed this up with correlational analysis and found that body weight was significantly, inversely correlated with relative protein intakes at weeks one $\left(\mathrm{R}^{2}=-0.66, p<0.001\right)$ and nine $\left(\mathrm{R}^{2}=-0.56, p\right.$ $<0.001)$. Further exploration showed that when IET soldiers were binned into groups based on baseline BM, only those where week one BM five $\mathrm{kg}$ or more below average consumed 2 or more $\mathrm{g} / \mathrm{kg} /$ day of protein. Interestingly individuals $10 \mathrm{~kg}$ above average week one BM consumed only $1.7 \mathrm{~g} / \mathrm{kg} /$ day of protein. Organizational recommendations and systematic reviews of the literature suggest that daily protein intakes should be between 1.6 and 2 (50) and 1.7 and $2.2 \mathrm{~g} / \mathrm{kg} /$ day (51). Therefore, individuals with lower $\mathrm{BM}$ in our cohort were able to consume protein intakes on the higher end of the recommended ranges whereas individuals with higher BM were closer to the lower end of this range. These daily requirements may increase to $2-3$ $\mathrm{g} / \mathrm{kg} /$ day in individuals who train in energy-restricted conditions (52), such as may occur in IET (3). Collectively, this suggests that individuals with higher BM or FFM entering into IET may benefit from additional supplementation to help elevate protein intake to optimal levels to optimize the FFM response to training.

The overall group-by-time interaction for FFM was not significant $(p=0.07)$. However, the low $p$-value considered in light of that the WP group gained on average $1.2 \mathrm{~kg}$ of FFM vs. only $0.1 \mathrm{~kg}$ in $\mathrm{CHO}$ and had a larger effect size (WP $=0.1, \mathrm{CHO}=0$ ), suggests that WP may have a clinically relevant effect on FFM in IET soldiers. The lack of statistical significance in the current work may be due to the large response heterogeneity in the cohort. The change in FFM was 0.1 on average with a standard deviation of $3 \mathrm{~kg}$ in $\mathrm{CHO}$ and 1.2 with a standard deviation of $2.4 \mathrm{~kg}$ in the WP group. One potential driver of the variability in response in the $\mathrm{CHO}$ group is that protein intake from diet alone was adequate to maximize the FFM response to IET. Previous work in British IET, suggests that nitrogen balance can be attained, at least in the initial weeks, by consumption of $1.5 \mathrm{~g} / \mathrm{kg} /$ day of protein intake (53). Additionally, a meta-analysis summarizing the literature on supplementation in strenuous military environments suggested protein intakes between 1.7 and $2.2 \mathrm{~g} / \mathrm{kg} / \mathrm{day}$ are recommended (51). Here we report that the $\mathrm{CHO}$ group consumed on average $2.2 \mathrm{~g} / \mathrm{kg} /$ day. It is also possible that additional caloric intake from supplementation, in general, may be beneficial for FFM response to IET. Previously we reported that $90 \%$ of IET soldiers gained FFM when consuming two supplement servings per day (21). Overall, in this study, approximately $69 \%$ of all IET soldiers gained FFM when consuming one supplement serving per day. Other work reported only $36 \%$ of male soldiers gained FFM when no supplementation is given during IET (5). Thus, it is possible there is a dose-response benefit of additional energy intake during IET to combat the negative energy balance that has been previously reported during IET training (3). However, this distinction cannot be made in the current study due to the lack of direct comparison of one vs. two servings with a nonsupplemented control group. Future research needs to expand our work by comparing WP and $\mathrm{CHO}$ at various doses with a non-supplemented control group.

The body composition presented here should be interpreted with caution, due to the method used. Single-frequency bioelectrical impedance analysis of body composition, as used in the current investigation, has been reported to be a valid and reliable method for assessing body composition (54-56), but may under/over-predict FM and FFM $(55,57)$. Thus, caution should be used when drawing conclusions about the precise characterization of body composition of IET soldiers from the current investigation. However, the body composition responses to IET and supplementation presented in the current investigation should be considered reliable as controls were in place to optimize the reliability of the results. Estimation equation (54) and conditions prior to assessment (58) can impact the accuracy of SF BIA results. Here we used the Lukaski equation, which has been shown to be a valid estimator of FFM in comparison to hydrostatic underwater weighing and Dual X-ray Absorptiometry (DXA) $(56,57)$. To address the influence of conditions prior to assessment, we performed body composition measures at the same time of day (early morning), prior to exercise, in the fasted, hydrated state, all of which may impact body composition assessments in SF-BIA (58) and non-SF-BIA methods such as DXA $(59,60)$. Additionally, we aimed to minimize the influence of electrode placement by having the same team member perform electrode placement on 
all soldiers. Specifically, the body composition device used in this investigation has reliability in relation to FFM and FM as measured by DXA in obese and athletic populations but may underestimate FM and overestimate $\operatorname{FFM}(55,57)$.

Both the WP and $\mathrm{CHO}$ groups improved in overall performance during IET training. This was expected as the physical fitness program is designed to take untrained civilians and make them into trained tactical athletes. The lack of difference in endurance between the groups may be explained in the similar levels of carbohydrate consumption. Current recommendations for athletes involved in moderate, high, and very high volumes of exercise are 5-7 g/ kg/day, 6-10 g/ kg/day, and $8-12 \mathrm{~g} / \mathrm{kg} /$ day respectively to restore muscle glycogen stores that fuel endurance exercise $(61,62)$. IET soldiers experience training volumes in the high to very high range but are consuming carbohydrate intakes that are below or at best, on the lower range of the recommendations for their physical activity levels regardless of supplement groups $(3,4,61,62)$. Additionally, there was only a $1.1 \mathrm{~g} / \mathrm{kg} /$ day difference in carbohydrate intake between groups. Previous work has shown that a difference of 2 $\mathrm{g} / \mathrm{kg} /$ day of carbohydrate showed no difference in pro or macroglycogen (subfractions of muscle glycogen that are responsive to diet), only the combined total muscle glycogen levels (63). Therefore, the $1.1 \mathrm{~g} / \mathrm{kg} /$ day difference between groups may not have been large enough to elevate muscle glycogen stores to a level that would lead to substantial differences in endurance performance. Dietary intakes may also have contributed to the lack of statistical difference in push-up performance. Although there was a significant group difference at the end of IET, both groups increased relative protein intakes to at least 2.2 (WP: 2.5, CHO: 2.2) g/kg/day. Protein intakes at this level are at or above the upper amounts of the current recommended protein intakes for military populations and may have been adequate to support the strength adaptations in IET soldiers (51). Another possible contributor to this is the large variability in individual response. On the group level, there was a large effect size of WP (Cohen's D: 0.52) and a medium effect size of CHO (Cohens D: 0.35) and the WP group gained on average four more push-ups relative to the $\mathrm{CHO}$ group. This is similar to what we have previously reported (21). However, the standard deviation of the mean difference was thirteen for $\mathrm{CHO}$ with an average improvement of eight push-ups and nine for WP with an average improvement of twelve push-ups. Large variability in the response to IET has been shown elsewhere revealing very large improvements (over 100\% improvement) to even losses in push-up performance across training (64). The large variability along with the knowledge that we were only able to obtain physical performance data from three out of the four platoons, may have contributed to the lack of statistical significance in physical performance. Regarding the large variability in response across IET, future work would be highly impactful that is designed to explore the factors that contribute to the response variability so that the IET soldier's response to IET can be optimized.

Serum IGF-1, testosterone, and the T:C ratio significantly increased, whereas IL-6 decreased regardless of the supplementation group across the 8 weeks of IET. Physiologically, IGF-1 and testosterone play important roles in stimulating muscle protein synthesis $(65,66)$ and enhancing satellite cell activity to increase the myonuclear number and enhance hypertrophy $(67,68)$. Conversely, cortisol has catabolic effects on skeletal muscle (69) and its increase relative to the concentration of testosterone (T:C) has been related to decreases in performance in athletic environments (13). Studies in similar IET environments outside of the United States consistently show decreases in IGF-1 and increases in Cortisol. The testosterone response is more heterogeneous. One study showed an increase, another shows no change, whereas another shows an increase in initial weeks (1-4) followed by a decrease in the final weeks (5-7). Studies in US Army Ranger training have reported that IGF-1 and testosterone decrease in response to large volumes of training and inadequate energy intake $(8,70)$. Here, we report that regardless of supplement group, IGF-1 increased, and cortisol decreased, both of which the opposite typically occurs in military training environments. The biomarker decrease in previous studies was thought to reflect an imbalance between training volume and nutritional intake. This imbalance can be restored by increased nutritional intake (12). Therefore, it is possible that additional nutritional intake by supplementation, in general, is beneficial for the biomarker response to IET. However, this statement is limited in that the base, typical hormonal response to IET is not adequately characterized. More work is needed to establish the typical hormonal response to IET in United States IET environments.

We also report that IL- 6 decreased across IET. IL-6 is released post-exercise and plays a variety of roles, one of which is stimulating the inflammatory response to muscle damage (71). Chronic elevations in IL-6 have been linked to overtraining (20). Previous work in Israeli IET revealed there was no statistically significant change in IL-6 in male $(72)$ and female $(72,73)$ recruits across 4 months of training. Another study in Australian IET reported no change in IL-6 across 8 weeks of IET (74). We did not replicate these findings in the current investigation. One potential factor was that IET soldiers in our cohort consumed high levels of protein from their diet. One study in marathon runners showed that while supplementation with soy protein did not have an effect, individuals who consumed higher dietary protein (over $20 \%$ of daily caloric intake from protein) had a reduced IL-6 and overall inflammatory response to a marathon (75). Studies on the acute effect of protein supplementation vary in protein dose, type, and results as some report a reduction in IL-6 post-exercise (76) while others report no effect and suggest that meeting energy intake needs may be more important (77). These are all important considerations for the current results as they lend potential explanations for the IL- 6 response observed here. Overall participants: consumed on average $19 \%( \pm 2 \%)$ of daily calories from protein at week 9 and received additional caloric intake via calorie-matched supplements. Furthermore, participants for both groups had access to dietary protein in the post-exercise period as physical fitness training for Army IET soldiers occurs early in the morning and is followed by breakfast. It is also important to note that IL-6 also plays a key role in stimulating the immune response to pathogens (16) and is elevated by psychological stress (78). Therefore, it is possible that week 1 levels of IL- 6 could have been elevated at pre-intervention 
due to immunizations, close exposure to a new group of people coming from diverse locations, or stress. This would create an artificial elevation in IL- 6 at week 1 and appear to be a reduction in IL-6 across IET. Overall, similar to the hormonal response to IET, the inflammatory response to Army IET is not well characterized and more work needs to be done to characterize the typical inflammatory response of IET soldiers. Considering the collective catabolic (cortisol), inflammatory (IL-6), and anabolic (testosterone, IGF-1) hormonal response observed here, the physiologic environment seems to be one that is beneficial for optimal response to IET.

Although secondary, there were two interesting findings regarding diet and physical activity. Of concern was that supplementation would not be additional nutrition to the soldier's diet but would instead lead to decreased caloric consumption during meals. To address this, we collected diet logs before implementation of supplementation during the baseline week, allowing us to compare dietary intake from the dining facility alone at baseline to see if there was an increase in food consumption across IET. Here, as in our past investigation (21), we report that IET soldiers increased dietary intake from meals consumed from the dining facility and that both groups in the current investigation increased absolute and relative (relative to body weight) macronutrient intake across IET. It is important to note that this was not a primary aim of this investigation and, therefore, future research needs to be conducted to determine if supplementation does negatively impact food consumption. Another secondary important finding from this study is that physical activity (i.e., training volume) was significantly different across the IET phase. The red phase (first 3 weeks of IET) was significantly higher in time spent in light activity than all other phases and on average had the highest total training volume. This is in agreement with our previous work that found training volume was higher during the initial weeks of training $(3,4)$. Reports from the Center for Disease Control (CDC) suggest that $<30 \%$ of individuals in the U.S. aged $18-35$ participate in 300 min per week of moderate or 150 min of vigorous-intensity exercise (79). Here, we report that IET soldiers participate in over $400 \mathrm{~min}$ per day of at least light intensity exercise. Thus, IET soldiers may experience rapid increases in training volume as they perform more physical activity in 1 day than much of the US population performs in 1 week. US Army training command has been working to resolve these issues.

What should finally be noted is how the current dataset relates to our previous study where IET Soldiers were provided two servings of WP vs. a calorie-matched $\mathrm{CHO}$ supplement (21). The current investigation was conducted in a separate cohort, with different IET cadre, military occupation specialty, and training, with only one serving of WP or CHO once per day. The mean differences (WP minus CHO) for FFM were 1.1 (single serving) and 0.6 (two servings) $\mathrm{kg}$ higher in the WP vs. CHO groups. WP decreased FM 1.2 (single serving) and 1.8 (two servings) kg more on average and improved push-up performance on average about 4.3 (single servings) and 4.2 (two servings), relative to the change in the $\mathrm{CHO}$ group. Though not all of these were determined to be statistically significant, the consistency of these results, even though IET cohort and leadership were different, suggest that WP
TABLE 5 | Consistency of between group mean differences across cohorts.

\begin{tabular}{llcc}
\hline Variable & Group & $\begin{array}{c}\text { Single WP/CHO serving } \\
\text { Mean Difference }[\mathbf{C l}]\end{array}$ & $\begin{array}{c}\text { Two WP/CHO servings } \\
\text { Mean Difference [Cl] }\end{array}$ \\
\hline FFM (kg) & CHO & $0.1[-5.8,5.9]$ & $3.6[2.3,4.9]$ \\
& WP & $1.2[-3.5,5.8]$ & $4.2[3.1,5.4]$ \\
& Diff & 1.1 & 0.6 \\
FM (kg) & CHO & $-0.9[-5.9,4.1]$ & $-2.7[-4.0,-1.3]$ \\
& WP & $-2.1[-7.8,3.6]$ & $-4.5[-5.8,-3.2]$ \\
& Diff & -1.2 & -1.8 \\
PU (reps) & CHO & $7.8[-17.3,32.9]$ & $2.6[-0.7,6.0]$ \\
& WP & $12.1[-5.8,30.1]$ & $6.8[2.9,10.7]$ \\
& Diff & 4.3 & 4.2 \\
\hline
\end{tabular}

Mean difference: the average difference across IET with 95\% Cls at weeks 1 and 9 for FFM and FM and weeks 2 and 8 for PU. Diff, Mean Difference in WP minus Mean Difference in CHO. FFM, Fat-Free Mass; FM, Fat Mass; PU, Push-ups completed in 1 min; WP, Whey protein supplement group; $\mathrm{CHO}$, Carbohydrate supplement group.

may benefit body composition changes and strength endurance during IET. More information on comparisons between our prior and current studies can be found in Table 5.

There are limitations to this study. One limitation in this study was that performance data was obtained from $75 \%$ of the participants. This resulted in more data being collected for the WP group in comparison to the $\mathrm{CHO}$. We were still able to obtain $55(\mathrm{WP}=37, \mathrm{CHO}=17)$ data points. Another limitation is that performance data was collected by multiple testers. While inter-rater reliability could influence the findings of this study, it is notable that drill sergeants administered all tests and are highly trained in conducting the APFT. They administer the test often and IET soldier graduation is dependent upon the APFT. Caution should be taken regarding the body composition results (critiqued in detail above). While the reliability of a single frequency has been established previously (54-56), the characterization of true FFM and FM may not be as precise as other methods such as underwater weighing and DXA $(55,57)$. Regarding the analysis of biomarkers, it is notable that blood draws were collected only at the week 1 and week 9-time points due to limited access to the soldiers during the IET period. Ideally, more sampling time points would be completed to better describe the typical hormonal and inflammatory response of soldiers to Army IET environments, which is not well characterized. Another limitation is the timing of supplement consumption. We were able to record adherence to consuming supplementation but were not able to gather adherence as to the time of consumption/dispersion of supplements being before bed. Drill sergeants were asked to disperse and IET soldiers were instructed to consume supplements before bed, but the research team was not present due to trying to be minimally invasive into the IET training schedule. Finally, our discussion of the potential influence of supplement dose (one vs. two servings) must be considered in the context that we did not perform a direct comparison in this investigation. Our work investigating two servings per day was completed previously in a different IET cohort (21). 


\section{CONCLUSION}

Once-daily supplementation with WP significantly decreased FM and enhanced gains in FFM in individuals who entered IET with higher FFM compared to those with lower FFM. The consistency of mean changes and effect sizes in FM and FFM and previous cohorts of Army IET suggest that WP may be beneficial for soldiers' body composition response during IET. However, there was no significant influence of WP on physical performance or biomarkers of the physiologic response to IET. The lack of response may be due to high relative dietary protein intakes in IET soldiers in the current cohort or may suggest that more than one serving is needed to optimize performance.

\section{DATA AVAILABILITY STATEMENT}

The datasets presented in this article are not readily available because of Army data sharing restrictions. They may be available upon special arrangement. Requests to access the datasets should be directed to jms0018@auburn.edu.

\section{ETHICS STATEMENT}

The studies involving human participants were reviewed and approved by the Auburn University Institutional Review Board, and the Director, Research and Analysis Directorate Army Center. The patients/participants provided their written informed consent to participate in this study.

\section{AUTHOR CONTRIBUTIONS}

JM, JS, KY, KRL, and MDR: conceptualization. JM, JS, DB, $\mathrm{PM}, \mathrm{KY}, \mathrm{KRL}, \mathrm{MDR}$, and KDL: methodology. JM, CH, PM, and KRL: software/analysis. JM, JS, CH, PM, PR, KY, KRL, and MDR: validation. JM, PM, KY, and KRL: formal analysis. JS, JM, KDL, DB, CH, MAR, PM, PR, KY, KRL, and MDR: investigation. JS and MDR: resources. JS, JM, KDL, DB, CH, MAR, PM, PR, KY, and MDR: data collection and quality

\section{REFERENCES}

1. DOD US Army. US. Army field manual (FM) 21-20, Physical Fitness Training. In: Army Dot, editor. Washington, DC: U.S. Army Training and Doctrine Command; Department of Defense. (1998).

2. Sharp M, Patton J, Vogel J. A Database of Physically Demanding Tasks Performed by US Army Soldiers. Natick MA: Army Research Inst oF Environmental Medicine (1998).

3. McAdam J, McGinnis K, Ory R, Young K, Frugé AD, Roberts M, et al. Estimation of energy balance and training volume during Army Initial Entry Training. J Int Soc Sports Nutr. (2018) 15:55. doi: 10.1186/s12970-018-0262-7

4. Simpson K, Redmond J, Cohen B, Hendrickson N, Spiering B, Steelman R, et al. Quantification of physical activity performed during US Army Basic Combat Training. US Army Med Dep J. (2013) 4:55-65. doi: 10.21236/ADA610831

5. Margolis L, Pasiakos S, Karl J, Rood J, Cable S, Williams K, et al. Differential effects of military training on fat-free mass and plasma amino acid adaptations in men and women. Nutrients. (2012) 4:2035-46. doi: 10.3390/nu41 22035 assurance. JM, JS, and MDR: writing-original draft preparation and funding acquisition. JS, KDL, DB, CH, MAR, PM, PR, KY, KRL, and MDR: writing-review and editing. JM and MDR: visualization. JS and JM: supervision. JS, JM, KDL, and MDR: project coordination/administration. All authors contributed to the article and approved the submitted version.

\section{FUNDING}

Funding for data collection and conduction of this study were provided by the Warrior Research Center. Both WP and $\mathrm{CHO}$ supplements were donated to the Warrior Research Center by Bionutritional Research Group (Irvine, CA, USA) and Hilmar Ingredients (Hilmar, CA, USA). Dr. Chris Lockwood of Lockwood, LLC (C.M.L., Draper, UT, USA) solicited these donations and provided additional financial support in ensuring that products were formulated, tested for content, and blinded accordingly.

\section{ACKNOWLEDGMENTS}

The authors would like to say thank you to all the IET soldiers for their participation in this study and the cadre for their assistance and service. The authors would like to thank Kevin Lawrence at Bionutrtional Research Group and Dr. Chao Wu at Hilmar Ingredients for the supplements that were provided for this study. The authors would also like to thank JW Nutritional for all manufacturing, packaging, non-active ingredients, and all costs involving analytical testing of raw materials and finished products for identity, purity, potency, and composition. Moreover, we appreciate Dr. Lockwood's assistance, as his efforts were critical in procuring nutritional supplements suitable for executing this study in a double-blinded fashion. Lastly, we would like to thank all of our undergraduate and master's students who assisted in data collection for this project: Alex Brown, Sarah Gordon, Josh Ourada, Bryce Munz, Jordan Devine, Krystal Bell, Jessica Nendze, and Rian Ory. Without the help of everyone listed, completion of this project would not have been possible.

6. Margolis LM, Murphy NE, Martini S, Spitz MG, Thrane I, McGraw SM, et al. Effects of winter military training on energy balance, whole-body protein balance, muscle damage, soreness, and physical performance. Appl Physiol Nutr Metab. (2014) 39:1395-401. doi: 10.1139/apnm-2014-0212

7. Flakoll PJ, Judy T, Flinn K, Carr C, Flinn S. Postexercise protein supplementation improves health and muscle soreness during basic military training in Marine recruits. J Appl Physiol (1985). (2004) 96:9516. doi: 10.1152/japplphysiol.00811.2003

8. Nindl B, Barnes B, Alemany J, Frykman P, Shippee R, Friedl K. Physiological consequences of US Army Ranger training. Med Sci Sports Exerc. (2007) 39:1380-7. doi: 10.1249/MSS.0b013e318067e2f7

9. Fortes M, Diment B, Greeves J, Casey A, Izard R, Walsh N. Effects of a daily mixed nutritional supplement on physical performance, body composition, and circulating anabolic hormones during 8 weeks of arduous military training. Appl Physiol Nutr Metab. (2011) 36:967-75. doi: 10.1139/h1 $1-124$

10. Nindl B, Alemany J, Kellogg M, Rood J, Allison S, Young A, et al. Utility of circulating IGF-I as a biomarker for assessing body composition changes in men during periods of high physical activity superimposed 
upon energy and sleep restriction. J Appl Physiol. (2007) 103:3406. doi: 10.1152/japplphysiol.01321.2006

11. Kraemer W, Ratamess N. Hormonal responses and adaptations to resistance exercise and training. Sports Med. (2005) 35:33961. doi: 10.2165/00007256-200535040-00004

12. Friedl K, Moore R, Hoyt R, Marchitelli L, Martinez-Lopez L, Askew E. Endocrine markers of semistarvation in healthy lean men in a multistressor environment. J Appl Physiol. (2000) 88:1820-30. doi: 10.1152/jappl.2000.88.5.1820

13. Kraemer W, French D, Paxton N, Hakkinen K, Volek J, Sebastianelli W, et al. Changes in exercise performance and hormonal concentrations over a big ten soccer season in starters and nonstarters. J Strength Conditioning Res. (2004) 18:121-8. doi: 10.1519/00124278-200402000-00018

14. Diment B, Fortes M, Greeves J, Casey A, Costa R, Walters R, et al. Effect of daily mixed nutritional supplementation on immune indices in soldiers undertaking an 8-week arduous training programme. Eur J Appl Physiol. (2012) 112:1411-8. doi: 10.1007/s00421-011-2096-8

15. Drain J, Groeller H, Burley S, Nindl B. Hormonal response patterns are differentially influenced by physical conditioning programs during basic military training. J Sci Med Sport. (2017) 20:S98-S103. doi: 10.1016/j.jsams.2017.08.020

16. Tanaka T, Narazaki M, Kishimoto T. IL-6 in inflammation, immunity, and disease. Cold Spring Harb Perspect Biol. (2014) 6:a016295. doi: 10.1101/cshperspect.a016295

17. Suzuki K, Peake J, Nosaka K, Okutsu M, Abbiss C, Surriano R, et al. Changes in markers of muscle damage, inflammation and HSP70 after an Ironman Triathlon race. Eur J Appl Physiol. (2006) 98:52534. doi: 10.1007/s00421-006-0296-4

18. Gomez-Merino D, Chennaoui M, Burnat P, Drogou C, Guezennec C. Immune and hormonal changes following intense military training. Mil Med. (2003) 168:1034-8. doi: $10.1093 / \mathrm{milmed} / 168.12 .1034$

19. McClung J, Martini S, Murphy N, Montain S, Margolis L, Thrane I, et al. Effects of a 7-day military training exercise on inflammatory biomarkers, serum hepcidin, and iron status. Nutr J. (2013) 12:141. doi: 10.1186/1475-2891-12-141

20. Gholamnezhad Z, Boskabady M, Hosseini M, Sankian M, Rad A. Evaluation of immune response after moderate and overtraining exercise in wistar rat. Iran J Basic Med Sci. (2014) 17:1.

21. McAdam JS, McGinnis KD, Beck DT, Haun CT, Romero MA, Mumford PW, et al. Effect of Whey Protein Supplementation on Physical Performance and Body Composition in Army Initial Entry Training Soldiers. Nutrients. (2018) 10:1248. doi: 10.3390/nu10091248

22. Willoughby D, Stout J, Wilborn C. Effects of resistance training and protein plus amino acid supplementation on muscle anabolism, mass, and strength. Amino Acids. (2007) 32:467-77. doi: 10.1007/s00726-006-0398-7

23. Ballard T, Clapper J, Specker B, Binkley T, Vukovich M. Effect of protein supplementation during a 6-mo strength and conditioning program on insulin-like growth factor I and markers of bone turnover in young adults-. Am J Clin Nutr. (2005) 81:1442-8. doi: 10.1093/ajcn/81.6.1442

24. Kraemer W, Solomon-Hill G, Volk B, Kupchak B, Looney D, Dunn-Lewis $\mathrm{C}$, et al. The effects of soy and whey protein supplementation on acute hormonal reponses to resistance exercise in men. J Am Coll Nutr. (2013) 32:66-74. doi: 10.1080/07315724.2013.770648

25. Sasaki J, John D, Freedson P. Validation and comparison of ActiGraph activity monitors. J Sci Med Sport. (2011) 14:411-6. doi: 10.1016/j.jsams.2011.04.003

26. Migueles J, Cadenas-Sanchez C, Ekelund U, Delisle Nystrom C, Mora-Gonzalez J, Lof $\mathrm{M}$, et al. Accelerometer data collection and processing criteria to assess physical activity and other outcomes: a systematic review and practical considerations. Sports Med. (2017) 47:1821-45. doi: 10.1007/s40279-017-0716-0

27. Brond J, Arvidsson D. Sampling frequency affects the processing of Actigraph raw acceleration data to activity counts. J Appl Physiol. (2016) 120:3629. doi: 10.1152/japplphysiol.00628.2015

28. R Core Team. R: A Language and Environment for Statistical Computing. $R$ Foundation for Statistical Computing, Vienna, Austria 2015. Vienna, Austria (2015). Available online at: https://www.R-project.org/

29. RStudio Team. RStudio: Integrated Development Environment for $R$. Boston, MA: RStudio, PBC (2014). Available online at: http://www.rstudio.com/
30. Wickham H, Francois R, Henry L, Müller K. dplyr: A Grammar of Data Manipulation. R package version 070 ed. (2017). Available online at: https:// CRAN.R-project.org/package $=$ dplyr

31. Wickham H, Henry L. tidyr: Easily Tidy Data with spread and gather Functions. R package version 070 ed. (2017). Available online at: https://CRAN.R-project. org/package $=$ tidyr

32. Wickham H. Reshaping data with the reshape package. J Stat Softw. (2007) 21:1-20. doi: 10.18637/jss.v021.i12

33. Lawrence M. ez: Easy Analysis and Visualization of Factorial Experiments. $\mathrm{R}$ package version 44-0 ed. (2016). Available online at: https://CRAN.R-project. org $/$ package $=\mathrm{ez}$

34. Fox J, Weisberg S. An $\{R\}$ Companion to Applied Regression. 2nd Edn. Thousand Oaks, CA: Sage Publicatons. (2011). Available online at: https:// socialsciences.mcmaster.ca/jfox/Books/Companion/

35. Pfaff B. VAR, SVAR and SVEC models: Implementation within R package vars. J Stat Softw. (2008) 27:1-32. doi: 10.18637/jss.v027.i04

36. Wickham H. ggplot2: Elegant Graphics for Data Analysis. New York, NY: Springer-Verlag (2009). Available online at: https://ggplot2.tidyverse.org/

37. Lukaski HC, Bolonchuk WW, Hall CB, Siders WA. Validation of tetrapolar bioelectrical impedance method to assess human body composition. J Appl Physiol (1985). (1986) 60:1327-32. doi: 10.1152/jappl.1986.60.4.1327

38. Sefton JM, Lohse K, McAdam J. Prediction of injuries and injury types in army basic training, infantry, armor, and cavalry trainees using a common fitness screen. J Athl Train. (2016) 51:849-57. doi: 10.4085/1062-6050-51.9.09

39. Philippas D. Analysis of Covariance (ANCOVA). Michalos AC, editor Dordrecht: Springer. (2014). doi: 10.1007/978-94-007-0753-5_82

40. Frestedt JL, Zenk JL, Kuskowski MA, Ward LS, Bastian ED. A wheyprotein supplement increases fat loss and spares lean muscle in obese subjects: a randomized human clinical study. Nutr Metab (Lond). (2008) 5:8. doi: 10.1186/1743-7075-5-8

41. Miller PE, Alexander DD, Perez V. Effects of whey protein and resistance exercise on body composition: a meta-analysis of randomized controlled trials. J Am Coll Nutr. (2014) 33:163-75. doi: 10.1080/07315724.2013.875365

42. Lockwood CM, Roberts MD, Dalbo VJ, Smith-Ryan AE, Kendall KL, Moon JR, et al. Effects of hydrolyzed whey versus other whey protein supplements on the physiological response to 8 weeks of resistance exercise in college-aged males. J Am Coll Nutr. (2017) 36:16-27. doi: 10.1080/07315724.2016.1140094

43. Mobley CB, Fox CD, Ferguson BS, Pascoe CA, Healy JC, McAdam JS, et al. Effects of protein type and composition on postprandial markers of skeletal muscle anabolism, adipose tissue lipolysis, and hypothalamic gene expression. J Int Soc Sports Nutr. (2015) 12:14. doi: 10.1186/s12970-015-0076-9

44. Sasaki H. Whey protein intake modulates lipid metabolism by transcriptionally affecting PPARs and SREBP1c and their downstream enzymes in mice. Food Nutr Sci. (2019) 10:1045. doi: 10.4236/fns.2019.109075

45. D'Souza K, Mercer A, Mawhinney H, Pulinilkunnil T, Udenigwe CC, Kienesberger PC. Whey peptides stimulate differentiation and lipid metabolism in adipocytes and ameliorate lipotoxicity-induced insulin resistance in muscle cells. Nutrients. (2020) 12:425. doi: 10.3390/nu12020425

46. Cogan KE, Carson BP, Patel B, Amigo-Benavent M, Jakeman PM, Egan B. Regulation of GLUT4 translocation in an in vitro cell model using postprandial human serum ex vivo. Exp Physiol. (2019) 104:8007. doi: 10.1113/EP087356

47. Crovetti R, Porrini M, Santangelo A, Testolin G. The influence of thermic effect of food on satiety. Eur J Clin Nutr. (1998) 52:4828. doi: 10.1038/sj.ejcn. 1600578

48. Kassis A, Moille S, Nielsen-Moennoz C, Godin J-P, Sauser J, Monnard I, et al. Acute thermic effect of food in response to consumption of whey protein microgels in overweight adults. FASEB J. (2015) 29:746.5. doi: 10.1096/fasebj.29.1_supplement.746.5

49. Acheson KJ, Blondel-Lubrano A, Oguey-Araymon S, Beaumont M, Emady-Azar S, Ammon-Zufferey C, et al. Protein choices targeting thermogenesis and metabolism1-3. Am J Clin Nutr. (2011) 93:52534. doi: 10.3945/ajen.110.005850

50. Jäger R, Kerksick CM, Campbell BI, Cribb PJ, Wells SD, Skwiat TM, et al. International society of sports nutrition position stand: protein and exercise. $J$ Int Soc Sports Nutr. (2017) 14:20. doi: 10.1186/s12970-017-0177-8

51. Chapman S, Chung HC, Rawcliffe AJ, Izard R, Smith L, Roberts JD. Does protein supplementation support adaptations to arduous concurrent 
exercise training? A systematic review and meta-analysis with military based applications. Nutrients. (2021) 13:1416. doi: 10.3390/nu13051416

52. Helms E, Zinn C, Rowlands D, Brown S. A systematic review of dietary protein during caloric restriction in resistance trained lean athletes: a case for higher intakes. Int J Sport Nutr Exerc Metab. (2014) 24:12738. doi: 10.1123/ijsnem.2013-0054

53. Chapman S, Rawcliffe AJ, Izard R, Jacka K, Tyson H, Smith L, et al. Dietary intake and nitrogen balance in british army infantry recruits undergoing basic training. Nutrients. (2020) 12:2125. doi: 10.3390/nu12072125

54. Aandstad A, Holtberget K, Hageberg R, Holme I, Anderssen SA. Validity and reliability of bioelectrical impedance analysis and skinfold thickness in predicting body fat in military personnel. Mil Med. (2014) 179:20817. doi: 10.7205/MILMED-D-12-00545

55. Pateyjohns IR, Brinkworth GD, Buckley JD, Noakes M, Clifton PM. Comparison of three bioelectrical impedance methods with DXA in overweight and obese men. Obesity (Silver Spring). (2006) 14:206470. doi: $10.1038 /$ oby.2006.241

56. Ross R, Léger L, Martin P, Roy R. Sensitivity of bioelectrical impedance to detect changes in human body composition. J Appl Physiol (1985). (1989) 67:1643-8. doi: 10.1152/jappl.1989.67.4.1643

57. Company J, Ball S. Body composition comparison: bioelectric impedance analysis with dual-energy X-ray absorptiometry in adult athletes. Meas Phys Educ Exerc Sci. (2010) 14:186-201. doi: 10.1080/1091367X.2010.497449

58. Lukaski HC, Bolonchuk WW, Siders WA, Hall CB. Body composition assessment of athletes using bioelectrical impedance measurements. J Sports Med Phys Fitness. (1990) 30:434-40.

59. Tinsley GM, Morales E, Forsse JS, Grandjean PW. Impact of acute dietary manipulations on DXA and BIA body composition estimates. Med Sci Sports Exer. (2017) 49:823-832. doi: 10.1249/MSS.00000000000 01148

60. Toomey CM, McCormack WG, Jakeman P. The effect of hydration status on the measurement of lean tissue mass by dual-energy X-ray absorptiometry. Eur J Appl Physiol. (2017) 117:567-74. doi: 10.1007/s00421-017-3552-x

61. Murray B, Rosenbloom C. Fundamentals of glycogen metabolism for coaches and athletes. Nutr Rev. (2018) 76:243-59. doi: 10.1093/nutrit/nuy001

62. Kerksick CM, Arent S, Schoenfeld BJ, Stout JR, Campbell B, Wilborn CD, et al. International society of sports nutrition position stand: nutrient timing. $J$ Int Soc Sports Nutr. (2017) 14:33. doi: 10.1186/s12970-017-0189-4

63. Tarnopolsky MA, Zawada C, Richmond LB, Carter S, Shearer J, Graham $\mathrm{T}$, et al. Gender differences in carbohydrate loading are related to energy intake. J Appl Physiol (1985). (2001) 91:225-30. doi: 10.1152/jappl.2001.91. 1.225

64. Varley-Campbell J, Cooper C, Wilkerson D, Wardle S, Greeves J, Lorenc T. Sex-specific changes in physical performance following military training: a systematic review. Sports Med. (2018) 48:2623-40. doi: 10.1007/s40279-018-0983-4

65. White J, Gao S, Puppa M, Sato S, Welle S, Carson J. Testosterone regulation of Akt/mTORC1/FoxO3a signaling in skeletal muscle. Mol Cell Endocrinol. (2013) 365:174-86. doi: 10.1016/j.mce.2012.10.019

66. Crossland H, Timmons J, Atherton P. A dynamic ribosomal biogenesis response is not required for IGF-1-mediated hypertrophy of human primary myotubes. FASEB J. (2017) 31:5196-207. doi: 10.1096/fj.20170 0329R

67. Braga M, Bhasin S, Jasuja R, Pervin S, Singh R. Testosterone inhibits transforming growth factor- $\beta$ signaling during myogenic differentiation and proliferation of mouse satellite cells: potential role of follistatin in mediating testosterone action. Mol Cell Endocrinol. (2012) 350:3952. doi: 10.1016/j.mce.2011.11.019

68. Matheny Jr R, Nindl B, Adamo M. Minireview: Mechano-growth factor: a putative product of IGF-I gene expression involved in tissue repair and regeneration. Endocrinology. (2010) 151:865-75. doi: 10.1210/en.2009-1217

69. Kraemer WJ, Ratamess NA, Hymer WC, Nindl BC, Fragala MS. Growth Hormone(s), Testosterone, Insulin-Like Growth Factors, and Cortisol: Roles and Integration for Cellular Development and Growth With Exercise. Front Endocrinol (Lausanne). (2020) 11:33. doi: 10.3389/fendo.2020.00033

70. Alemany J, Nindl B, Kellogg M, Tharion W, Young A, Montain S. Effects of dietary protein content on IGF-I, testosterone, and body composition during 8 days of severe energy deficit and arduous physical activity. J Appl Physiol. (2008) 105:58-64. doi: 10.1152/japplphysiol.00005.2008

71. Reihmane D, Dela F. Interleukin-6: possible biological roles during exercise. Eur J Sport Sci. (2014) 14:242-50. doi: 10.1080/17461391.2013.776640

72. Nindl B, Scofield D, Strohbach C, Centi A, Evans R, Yanovich R, et al. IGFI, IGFBPs, and inflammatory cytokine responses during gender-integrated Israeli Army basic combat training. J Strength Conditioning Res. (2012) 26:S73-81. doi: 10.1519/JSC.0b013e31825d81ba

73. Merkel D, Moran D, Yanovich R, Evans R, Finestone A, Constantini N, et al. The association between hematological and inflammatory factors and stress fractures among female military recruits. Med Sci Sports Exer. (2008) 40:S691-S7. doi: 10.1249/MSS.0b013e318189560c

74. Tait JL, Bulmer S, Drain JR, Main LC. Associations between inflammatory markers and well-being during 12 weeks of basic military training. Eur J Appl Physiol. (2021) 121:849-60. doi: 10.1007/s00421-020-04554-8

75. Röhling M, McCarthy D, Berg A. Continuous Protein Supplementation Reduces Acute Exercise-Induced Stress Markers in Athletes Performing Marathon. Nutrients. (2021) 13:2929. doi: 10.3390/nu13092929

76. Kerasioti E, Stagos D, Jamurtas A, Kiskini A, Koutedakis Y, Goutzourelas $\mathrm{N}$, et al. Anti-inflammatory effects of a special carbohydrate-whey protein cake after exhaustive cycling in humans. Food Chem Toxicol. (2013) 61:426. doi: 10.1016/j.fct.2013.01.023

77. Pasiakos SM, Margolis LM, Murphy NE, McClung HL, Martini S, Gundersen Y, et al. Effects of exercise mode, energy, and macronutrient interventions on inflammation during military training. Physiol Rep. (2016) 4:e12820. doi: 10.14814/phy2.12820

78. Frank MG, Watkins LR, Maier SF. Stress-induced glucocorticoids as a neuroendocrine alarm signal of danger. Brain Behav Immun. (2013) 33:16. doi: 10.1016/j.bbi.2013.02.004

79. Center for Disease Control and Prevention. Nutrition, Physical Activity, and Obesity: Data, Trends, and Maps (2015). Available online at: https://www.cdc. gov/nccdphp/dnpao/data-trends-maps/index.html (accessed December 27, 2017).

Conflict of Interest: Supplements were donated to the Warrior Research Center by Bionutritional Research Group (Irvine, CA, USA) and Hilmar Ingredients (Hilmar, CA, USA). Dr. Chris Lockwood of Lockwood, LLC (C.M.L., Draper, UT, USA) solicited these donations. $\mathrm{CH}$ is employed by Fitomics, LLC. The data presented here are honestly presented without falsification, fabrication, or inappropriate manipulation.

The remaining authors declare that the research was conducted in the absence of any commercial or financial relationships that could be construed as a potential conflict of interest.

Publisher's Note: All claims expressed in this article are solely those of the authors and do not necessarily represent those of their affiliated organizations, or those of the publisher, the editors and the reviewers. Any product that may be evaluated in this article, or claim that may be made by its manufacturer, is not guaranteed or endorsed by the publisher.

Copyright (C) 2022 McAdam, Lyons, Beck, Haun, Romero, Mumford, Roberson, Young, Lohse, Roberts and Sefton. This is an open-access article distributed under the terms of the Creative Commons Attribution License (CC BY). The use, distribution or reproduction in other forums is permitted, provided the original author $(s)$ and the copyright owner(s) are credited and that the original publication in this journal is cited, in accordance with accepted academic practice. No use, distribution or reproduction is permitted which does not comply with these terms. 